patients with higher rates of CTEPH with less severe pulmonary haemodynamic changes.

\section{S119 LEFT VENTRICULAR DYSFUNCTION INFLUENCES SURVIVAL IN CONNECTIVE TISSUE DISEASE ASSOCIATED PULMONARY ARTERIAL HYPERTENSION BUT NOT IDIOPATHIC PULMONARY ARTERIAL HYPERTENSION}

${ }^{1}$ SF Crawley, ${ }^{1} \mathrm{KG}$ Blyth, ${ }^{1} \mathrm{LE}$ McLure, ${ }^{2} \mathrm{HJ}$ Dargie, ${ }^{1} \mathrm{AJ}$ Peacock. ${ }^{1}$ Scottish Pulmonary Vascular Unit, Glasgow, UK; ${ }^{2}$ Glasgow Cardiac Magnetic Resonance Unit, Glasgow, UK

\subsection{6/thoraxjnl-2014-206260.125}

Background Connective tissue disease - associated pulmonary artery hypertension (CTD-PAH) has a worse prognosis compared with idiopathic pulmonary arterial hypertension (IPAH). We investigated the prognostic significance of left and right cardiac dysfunction in IPAH and CTD-PAH.

Methods and results Between 2003 and 2011, patients with a new suspected diagnosis of pulmonary hypertension underwent diagnostic assessment including cardiac magnetic resonance (CMR) imaging and right heart catheterization (RHC). 138 patients fulfilled the criteria for pulmonary arterial hypertension, of which 74 were diagnosed with IPAH and 38 were diagnosed with CTD-PAH. At baseline, there was no significant difference in age, functional class, lung function or six-minute walk distance between the two groups. At CMR, both groups had right ventricular (RV) dilatation and impaired RV systolic function, but well preserved left ventricular (LV) ejection fraction. Patients with IPAH had greater right ventricular hypertrophy than those with CTD-PAH (VMI 1.16 v 0.99, p =
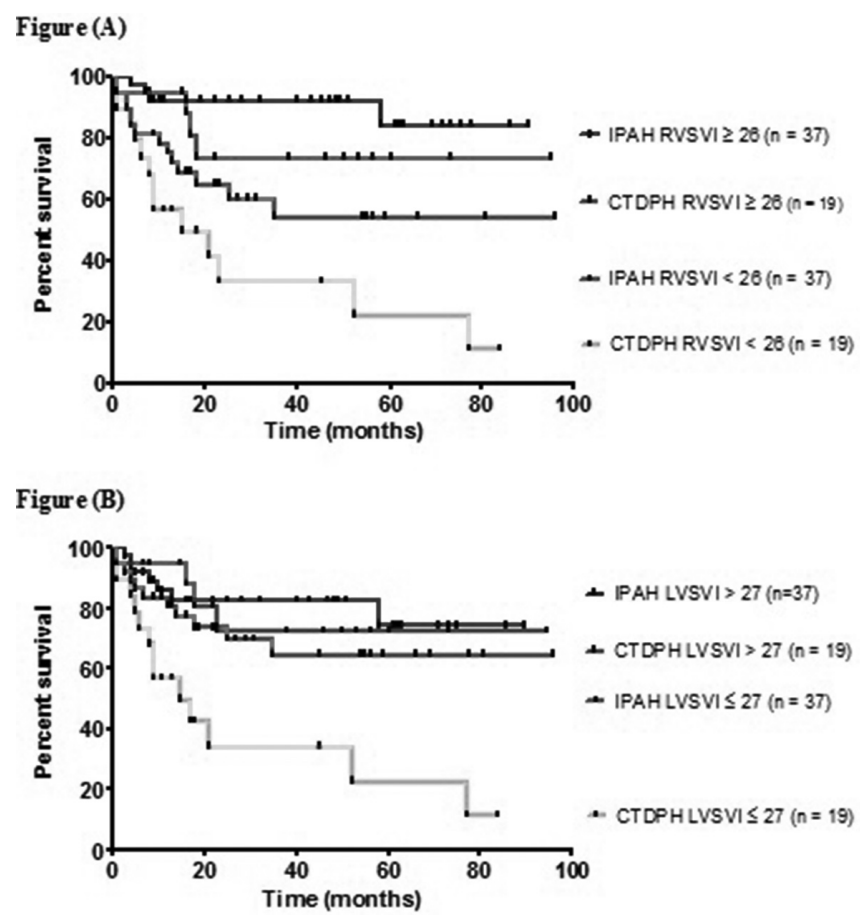

Abstract S119 Figure 1 Survival rates of patients stratified according to disease, and baseline RVSVI(A) or LVSVI (B). Poorer right ventricular function (inframedian RVSVI) was associated with impaired survival in both IPAH and CID-PAH (A). Poorer left ventricular function (inframedian LVSVI) was associated with impaired survival in CTD-PAH $(p=0.002)$, but not in $\operatorname{IPAH}(p=0.21)(B)$

RVSVI, right ventricular stroke volume index;LVSVI, left ventricular stroke volume index
0.03). Left atrial volume, a marker of LV diastolic dysfunction, was lower in IPAH than CTD-PAH $\left(23 \mathrm{v} 33 \mathrm{ml} / \mathrm{m}^{2}, \mathrm{p}<0.0001\right)$. At RHC, mean pulmonary artery pressure was higher in IPAH than CTD-PAH (50 v $43 \mathrm{mmHg}, \mathrm{p}=0.01)$.

There was no difference in the distribution of initial disease-targeted therapies between the groups. Survival was better in IPAH than in CTD-PAH ( $\mathrm{p}=0.03$ ), with rates of $83 \%$ at $1 \mathrm{yr}$ and $74 \%$ at 3 yrs in IPAH, but $75 \%$ at $1 \mathrm{yr}$ and $53 \%$ at 3 yrs in CTD-PAH. Poor baseline right ventricular function was associated with reduced survival in both conditions. However, poor left ventricular function, as measured by left ventricular stroke volume index (LVSVI), only influenced survival in CTD-PAH $(\mathrm{p}=0.002)$ and not in IPAH $(\mathrm{p}=$ $0.21)$.

Conclusions Poor LVSVI at diagnosis is associated with impaired survival in CTD-PAH but not IPAH. Intrinsic LV problems, particularly diastolic dysfunction, may contribute to the excess mortality in CTD-PAH.

\section{S120 RIGHT VENTRICULAR DYSFUNCTION IN PULMONARY HYPERTENSION WITH COMBINED PULMONARY FIBROSIS AND EMPHYSEMA SYNDROME}

${ }^{1} \mathrm{~A}$ S Swift, ${ }^{1} \mathrm{~S}$ Rajaram, ${ }^{1} \mathrm{D}$ Capener, ${ }^{2} \mathrm{C}$ Elliot, ${ }^{2} \mathrm{R}$ Condliffe, ${ }^{2} \mathrm{~J}$ Hurdman, ${ }^{2} \mathrm{DG}$ Kiely, ${ }^{1} \mathrm{JM}$ Wild. ${ }^{1}$ University of Sheffield, Sheffield, UK; ${ }^{2}$ Sheffield Pulmonary Vascular Disease Unit, Sheffield, UK

\subsection{6/thoraxjnl-2014-206260.126}

Introduction Recent studies have suggested that the coexistence of emphysema and fibrosis alters clinical outcome. The aim of this study was to investigate the comparative clinical characteristics, pulmonary function, haemodynamics and right ventricular (RV) function and outcome in patients with pulmonary hypertension associated with combined pulmonary fibrosis and emphysema (PH-$\mathrm{CPFE}$ ), chronic obstructive pulmonary disease (PH-COPD) and interstitial lung disease (PH-ILD).

Methods In 79, incident patients with pulmonary hypertension associated with respiratory disease, cardiovascular magnetic resonance imaging was performed at $1.5 \mathrm{~T}$. Emphysema and fibrosis were scored on high resolution computed tomography scans. Demographic data, lung function tests and right heart catheterisation were also performed.

Results Patients with pulmonary hypertension associated with combined pulmonary fibrosis and emphysema syndrome had lower right ventricular ejection fraction when compared to both patients with PH-COPD and PH -ILD $(\mathrm{p}<0.05)$. At KaplanMeier analysis, patients with $\mathrm{PH}-\mathrm{CPFE}$ patients had significantly

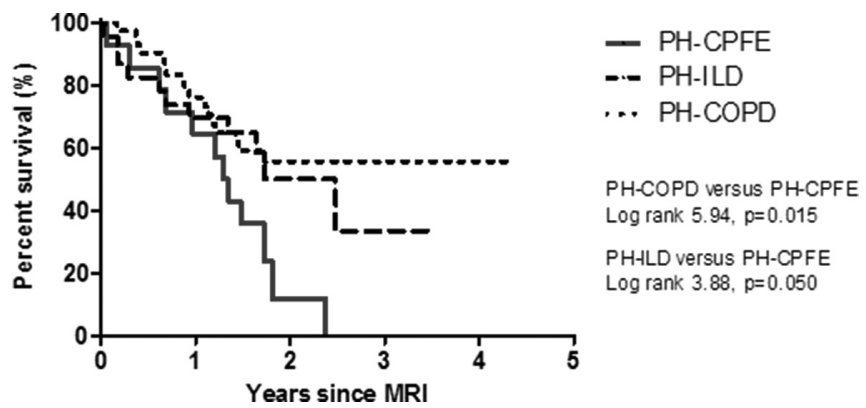

Abstract S120 Figure 1 Kaplan Meier plot showing survival of patients with pulmonary hypertension associated with combined fibrosis and emphysema (PH-CPFE) in comparison to pulmonary hypertension interstitial lung disease (PH-ILD) and pulmonary hypertension associated with COPD (PH-COPD) 